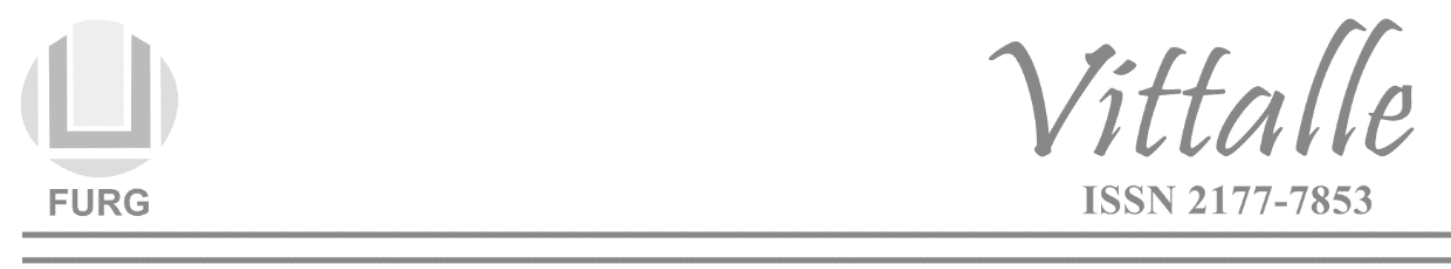

\title{
Distúrbios do Sódio
}

\section{Eduardo Borges Gomes, Hugo Cataud Pacheco Pereira*}

Faculdade de Medicina, Universidade Federal do Rio Grande, Rio Grande, RS, Brasil

\section{Palavras-chave:}

Hipernatremia;

Hiponatremia;

Homeostase; Sódio.

Keywords:

Hypernatremia;

Hyponatremia;

Homeostasis; Sodium.

\begin{abstract}
RESUMO
O sódio é o principal íon do espaço extracelular e é mantido em constante equilíbrio graças a um constante trabalho celular buscando a homeostase. Diversos distúrbios podem elevar ou diminuir sua concentração, levando a sérias consequências. Este capítulo aborda esses distúrbios, como reconhecê-los na prática clínica e corrigi-los, trazendo resumos, quadros e exercícios para facilitar o entendimento do leitor.
\end{abstract}

Sodium Disorders

\section{ABSTRACT}

Sodium is the main ion of the extracellular space and is kept in constant balance due to constant cellular work for homeostasis. Several disorders can increase or decrease its concentration, leading to serious consequences. This chapter discusses these disorders, how to recognize them in clinical practice and correct them, bringing summaries, charts and exercises to facilitate the reader's understanding.

\section{Introdução}

O sódio $(\mathrm{Na}+)$ é o principal íon impermeável do compartimento extracelular (CEC), tendo relação íntima com a água corporal e, consequentemente, com o volume circulante efetivo (VCE) (1-5). Isso se deve ao fato de que a concentração de sódio é responsável pela maior parcela da osmolaridade plasmática efetiva e da tonicidade, como pode ser constatado por meio da seguinte fórmula (1):

\section{Osmolaridade plasmática $=2 \times\left[\mathrm{Na}^{+}\right]+$Glicose $/ 18+$ Ureia/6}

Se considerarmos que, em condições fisiológicas, a osmolaridade plasmática média é de $290 \mathrm{mOsm} / \mathrm{L}$, que o valor de referência da glicose é $100 \mathrm{mg} / \mathrm{dL}$, que a ureia não é uma substância osmoticamente efetiva, portanto não contribuindo para osmolaridade efetiva e que o valor de referência médio do $\mathrm{Na}+$ é $140 \mathrm{mEq} / \mathrm{L}$, temos:

\section{Osmolaridade plasmática efetiva $=2 \times 140+100 / 18$ \\ Osmolaridade plasmática efetiva $=280+5,5$}

Ou seja, assim se nota que dos $290 \mathrm{mOsm} / \mathrm{L}$ do plasma, 280 são oriundos da concentração de $\mathrm{Na}+$, resultando uma parcela superior a $95 \%$ da osmolaridade efetiva total do plasma.

Dada a importância do Na+ no balanço hídrico, a sua concentração é finamente monitorada e regulada pelos vários mecanismos orgânicos: osmorreceptores, barorreceptores, mecanismos intra e extrarrenais, como o sistema renina angiotensina aldosterona (SRAA) e o peptídeo natriurético atrial (PNA), mantendo o $\mathrm{Na}+$ numa faixa

\footnotetext{
*Autor correspondente: hcppaguia@ vetorial.net (Pereira H.C.P.)
} 
fisiológica de 135 a $145 \mathrm{mEq} / \mathrm{L}(1,3-5)$.

\section{Hiponatremia}

\subsection{Definição}

É definida como a concentração de $\mathrm{Na}^{+}$inferior a $135 \mathrm{mEq} / \mathrm{L}$, sendo considerada o distúrbio eletrolítico mais comum nos pacientes hospitalizados $(1,3,4)$. Estima-se que de cada cinco pacientes internados, um terá hiponatremia (1). Na maioria dos casos, ocorre em função do aumento do volume de água do plasma, seja por retenção ou por aumento da oferta hídrica. Nessas situações, os rins são os protagonistas da remoção do excesso de água livre pela supressão da liberação do hormônio antidiurético (ADH), objetivando o aumento da concentração sérica de $\mathrm{Na}^{+}$. (1-5). O sistema renal começa a falhar nessa função quando excede a excreção de um volume de água superior a 10 litros em 24 horas (1).

\subsection{Etiologia}

Há várias doenças e situações que culminam na diminuição da concentração do $\mathrm{Na}+$ plasmático. Para detectar a causa da hiponatremia, pode-se dividir as suas etiologias conforme a volemia do paciente (4). Veja no Quadro 1:

Quadro 1 - Causas de hiponatremia.

\begin{tabular}{|c|c|c|}
\hline \multicolumn{3}{|c|}{$\begin{array}{c}\text { Classificações e causas de hiponatremia conforme a volemia } \\
\text { Hiponatremia Hipovolêmica }\end{array}$} \\
\hline Exame Físico & Achados laboratoriais & Exemplos \\
\hline Hipotensão Ortostática & Baixa osmolaridade plasmática & Perdas gastrointestinais \\
\hline Hipotensão arterial & Alta ureia plasmática & Perdas renais \\
\hline Taquicardia & Hipocalemia & Uso de diurético \\
\hline & Baixa osmolaridade urinária & Doença de Addison \\
\hline & Baixo sódio urinário & Aumento das perdas insensíveis \\
\hline & & Perda para terceiro espaço \\
\hline \multicolumn{3}{|c|}{ Hiponatremia Euvolêmica } \\
\hline \multirow[t]{8}{*}{ Exame Físico } & Achados laboratoriais & Exemplos \\
\hline & Baixa osmolaridade plasmática & SIAD \\
\hline & $\begin{array}{l}\text { Alta/baixa } \\
\text { urinária }\end{array}$ & Hipotireoidismo \\
\hline & Alto/baixo sódio urinário & Deficiência de glicocorticoide \\
\hline & & Trauma \\
\hline & & Doença do bebedor de cerveja \\
\hline & & Polidipsia \\
\hline & & Medicações e drogas \\
\hline \multicolumn{3}{|c|}{ Hiponatremia Hipervolêmica } \\
\hline Exame Físico & Achados laboratoriais & Exemplos \\
\hline Ascite & Baixa osmolaridade plasmática & Cirrose \\
\hline Edema & Baixa osmolaridade urinária & $\begin{array}{c}\text { Insuficiência } \\
\text { Congestiva } \\
\end{array}$ \\
\hline Anasarca & Baixo/alto sódio urinário & Síndrome Nefrótica \\
\hline & & Insuficiência renal \\
\hline \multicolumn{3}{|c|}{ Outras causas de hiponatremia (incluindo as de osmolaridades alta e normal } \\
\hline Adipsia primária ou secundária & Hiperglicemia extrema & Mieloma múltiplo \\
\hline Hipodipsia & Hipertrigliceridemia & Hiperlipidemia \\
\hline Aumento da ureia & Insuficiência adrenal & Manitol \\
\hline
\end{tabular}

Fonte: Harring et al. 2014 (4). 


\subsection{Quadro Clínico}

Na maioria das vezes, os pacientes hiponatrêmicos se apresentam assintomáticos. Os sintomas dependem basicamente do quão intenso foi a diminuição da concentração do $\mathrm{Na}+$ sérico e da rapidez que se deu essa mudança. Isso ocorre devido a capacidade das células nervosas de se adaptar à nova tonicidade do plasma, eliminando solutos orgânicos (principalmente glutamato, mioinositol e taurina) para equilibrar o tonicidade intracelular com a do meio extracelular. Estima-se um período de 48 horas para essa adaptação das células nervosas. Assim, os sintomas neurológicos podem estar ausentes. Caso não haja tempo para esse mecanismo adaptativo, o meio intracelular passa a adquirir uma tonicidade superior ao do extracelular, de modo que o gradiente osmótico passa a se inverter, fazendo com que a água ingresse nas células nervosas, gerando o quadro de edema cerebral. Dessa forma, náuseas e vômitos são os sintomas mais precoces, ocorrendo quando o $\mathrm{Na}+$ sérico estiver na faixa de 130 a $125 \mathrm{mEq} / \mathrm{L}$, sendo classificado como hiponatremia moderada. Quando inferior a $125 \mathrm{mEq} / \mathrm{L}$, hiponatremia severa, podem haver cefaleia, cãibras, letargia e hiporreflexia podem estar presentes. Abaixo de $115-120 \mathrm{mEq} / \mathrm{L}$, o paciente pode ter convulsões, respiração de Cheyne Stokes, hipotermia, coma, parada respiratória, herniação cerebral, lesão cerebral permanente e até ir ao óbito. É importante salientar que os sintomas nem sempre se associam ao grau da hiponatremia (1-4).

\subsection{Diagnóstico}

O diagnóstico etiológico pode ser inferido por meio da análise de 4 parâmetros laboratoriais:

a. Osmolaridade plasmática

Está reduzida na maioria dos casos de hiponatremia. Porém, pode estar normal ou até aumentada como nos casos de hiperlipidemia, hiperparaproteinemia ou na reabsorção de glicina durante a cirurgia de ressecção transuretral prostática (1-3).

b. Osmolaridade urinária (Uosm)

Reflete a ação do ADH no contexto de hiponatremia. Em situações em que a osmolaridade plasmática esteja diminuída, deve-se investigar se a água livre está sendo retida ou sendo excretada, indicando polidipsia primária. Neste último caso, o indivíduo já ingeriu tanta água, que o ADH está suprimido, eliminando a água livre e deixando a urina mais diluída possível. Isso se evidencia laboratorialmente com uma urina cuja a osmolaridade está abaixo de $100 \mathrm{mOsm} / \mathrm{kg}$ e densidade < 1.003 (1). Se os valores estiverem acima dos valores apresentados, é provável que o ADH esteja sendo secretado continuamente, retendo a água livre e deixando a urina menos concentrada. A fórmula para o cálculo está apresentada abaixo:

$$
\text { Uosm }=2 \times\left(\left[\mathrm{Na}^{+}\right]_{\text {urina }}+\left[\mathrm{K}^{+}\right]_{\text {urina }}\right)+[\text { Ureia }]_{\text {urina }} / 6+[\text { Glicose }]_{\text {urina }} / 18
$$

c. Concentração de Na+ urinário (valores de referência)

Muito útil no caso de uma hiponatremia hipoosmolar, para a distinção das duas principais causas, após a exclusão da insuficiência adrenal e hipotireoidismo, que são a hipovolemia e a Síndrome da Secreção Inapropriada do Hormônio Antidiurético (SIAD). A melhor maneira de explicar sobre essa distinção é por meio da fisiologia. No caso da SIAD, a reabsorção renal estará aumentada, tendo mais água livre no plasma, o que causará uma hiponatremia dilucional e uma expansão da volemia. As repercussões disso são: 
- Incremento do débito cardíaco, que aumentará a taxa de filtração glomerular (TFG) e reduzirá a reabsorção proximal de sódio;

- Diminuição da secreção de renina e de aldosterona;

- Aumento da secreção do PNA, após a maior distensão do átrio direito.

Dessa forma, justifica-se os critérios que caracterizam a SIAD, apresentados no Quadro 2 (7):

Quadro 2 - Critérios da Secreção Inapropriada do Hormônio Antidiurético (SIAD).

1) Osmolaridade plasmática baixa $(<270 \mathrm{mOsm} / \mathrm{kg})$;

2) Osmolaridade urinária inapropriadamente alta (>100 mOsm/kg);

3) Concentração de sódio urinário acima de $30 \mathrm{mEq} / \mathrm{L}$;

4) Euvolemia

5) Funções tireoidiana e adrenal normais.

Outros achados que tem alto valor preditivo para SIAD são a Fração de Excreção de ácido úrico > 12\% (que não sofre interferência dos diuréticos), e, principalmente, o sódio urinário (sofre interferência dos diuréticos) superior a $30 \mathrm{mEq} / \mathrm{L}$ e a Fração de Excreção de ureia superior a $55 \%$ (3).

Após ter sido preenchido os critérios de SIAD, deve-se diferenciá-la da síndrome perdedora de sal cerebral $(1,7)$. Esta se diferencia por ter uma inabilidade na reabsorção de Na+ por causa da liberação de um hormônio natriurético e um peptídeo natriurético oriundos do cérebro. Dessa forma, essa síndrome tem uma fisiopatologia muito semelhante ao da SIAD. Entretanto, não se sabe o exato mecanismo, a hipouricemia está presente na síndrome perdedora de sal. Assim, recomenda-se dosar o ácido úrico do paciente com suspeita de SIAD $(1,3,7)$. Outro dado que pode auxiliar na distinção, é a volemia do paciente: na SIAD o paciente está normovolêmico, enquanto na outra está hipovolêmico (1-3).

d. Equilíbrio acidobásico e de potássio

Nos casos dos pacientes com hiponatremia (Quadro 3) de etiologia desconhecida, essa relação pode ser útil (1). Veja os exemplos:

Quadro 3 - Hiponatremia desconhecida.

- Alcalose metabólica com hiponatremia e hipocalemia $\rightarrow$ sugestivo do uso de diuréticos ou vômitos;

-Acidose metabólica com hiponatremia e hipocalemia $\rightarrow$ sugestivo do uso abusivo de laxantes ou de intensa diarreia;

- Acidose metabólica com hiponatremia e hipercalemia $\rightarrow$ sugere insuficiência adrenal.

\subsection{Tratamento}

O tratamento depende da etiologia e do quadro clínico do paciente. Portanto, há algumas formas de tratamento (1-4): 
- Restrição hídrica: é considerada a primeira opção para pacientes normo ou hipervolêmicos, limitando a ingesta hídrica para menos de $1000 \mathrm{~mL} /$ dia. É a opção de tratamento para a maioria das hiponatremias, principalmente para as assintomáticas.

- Incremento de solução salina: opção terapêutica recomendada para pacientes hipovolêmicos ou com insuficiência adrenal. Pode ser realizada por meio do aumento do sal na dieta ou na infusão endovenosa, de soro fisiológico $0,9 \%$, por exemplo. A solução hipertônica $(\mathrm{NaCl}$ a $3 \%)$ está indicada para pacientes com hiponatremia sintomática, exceto para pacientes hipervolêmicos. Estes, se sintomáticos, devem receber a $\mathrm{NaCl} 3 \%$ juntamente com diuréticos de alça.

- Furosemida: é um diurético de alça indicado para pacientes euvolêmicos ou hipervolêmicos, com dificuldade de excretar a água livre (osmolaridade urinária $>200$ $\mathrm{mOsm} / \mathrm{kg}$ de água). Recomenda-se administrar juntamente com a solução hipertônica e restrição hídrica $(1,3)$.

- Antagonista do receptor da vasopressina (vaptanos): agente farmacológico capaz de produzir a diurese seletiva da água, mantendo os níveis normais de excreção do sódio e do potássio. Apesar de não ser de uso amplo no Brasil, está indicado quando há refratariedade à restrição hídrica, no caso de hiponatremia crônica (3).

- Ureia: Atua na indução da diurese osmótica, tendo eficácia semelhante ao vaptanos, porém com menor incidência de complicação por desmielinização. É opção terapêutica a ser considerada nos casos de SIAD e hiponatremia crônica (3).

O tratamento da hiponatremia tem uma peculiaridade de extrema importância: a velocidade de correção. Isso se deve ao fenômeno da desmielinização osmótica ou também conhecido como mielinólise pontina, uma patologia decorrente da correção rápida da hipotonicidade do plasma quando as células do sistema nervoso central (SNC) ainda estão adaptadas (após 48 horas de hiponatremia as células já iniciaram o processo de adaptação) para a tonicidade diminuída do CEC. Ou seja, nessa condição o meio interno das células nervosas está com a sua tonicidade diminuída em relação ao meio extracelular que aumentou a sua tonicidade subitamente numa correção equivocada. Dessa forma, o gradiente osmótico favorece o CEC, desidratando a célula e causando a desmielinização pontina e extrapontina. (1-4). Assim se estabelecem lesões neurológicas irreversíveis ou reversíveis que variam de disfagia até o óbito do paciente. As alterações de imagem, tanto na tomografia computadorizada quanto na ressonância, são evidenciadas na quarta semana após as lesões (1).

Portanto, a velocidade de correção não deve ultrapassar $10-12 \mathrm{mEq} / \mathrm{L} / \mathrm{dia}$, pois acima desses valores as chances de mielinólise pontina aumentam exponencialmente. Há populações com maior risco para complicarem com a desmielinização, que são os pacientes com hipocalemia, alcoólatras, desnutridos e hepatopatas (1-4,6). Para esses, a velocidade de correção não deve ser maior que $8 \mathrm{mEq} /$ dia. Ao comparar as taxas de correções recomendadas antigamente com as atuais, percebe-se uma tendência cada vez mais conservadora. Nos anos 90, a taxa recomendada era de até $20 \mathrm{mEq} / \mathrm{dia}$ (3). Hoje, um dos maiores especialistas no assunto, Madias, recomenda uma correção de 6-8 mEq/dia $(2,3)$. Assim, é recomendado um valor mais baixo, com uma margem de segurança: 8 a $12 \mathrm{mEq} / \mathrm{L} /$ dia. Nas situações em que a hiponatremia não seja relevante para a piora do status clínico do paciente, correções mais conservadoras como $6 \mathrm{mEq} / \mathrm{dia}$ são recomendadas. O Quadro 4 abaixo resume o tratamento indicado em suas respectivas situações (2-4). 
Quadro 4 - Tratamento da hiponatremia.

\begin{tabular}{|c|c|}
\hline Situação & Tratamento \\
\hline \multirow[t]{2}{*}{ Hiponatremia a Aguda ou Sintomática } & $\begin{array}{l}\text { Sintomas Graves: Bôlus } \mathrm{NaCl} 3 \% \\
(100 \mathrm{~mL} \text { em } 10 \mathrm{~min}, \text { em até } 3 \text { vezes se } \\
\text { necessário })\end{array}$ \\
\hline & $\begin{array}{l}\text { Sintomas moderados: Infusão contínua } \\
\mathrm{NaCl} 3 \% \text { (0.5-2 } \mathrm{ml} / \mathrm{kg} \text { por hora) }\end{array}$ \\
\hline \multirow{2}{*}{$\begin{array}{l}\text { Hiponatremia Crônica (> } 48 \text { horas) ou de } \\
\text { duração indeterminada } \\
\text { SIAD }\end{array}$} & $1^{\text {a }}$ linha: Restrição hídrica \\
\hline & $2^{\mathrm{a}}$ linha: Demeclociclina, ureia ou vaptan \\
\hline Hiponatremia Hipovolêmica & Salina isotônica \\
\hline \multirow[t]{2}{*}{ Hiponatremia Hipervolêmica } & Restrição hídrica \\
\hline & Vaptans \\
\hline \multirow[t]{2}{*}{ Correções } & $\begin{array}{l}\text { Mínimo: } 4-8 \mathrm{mEq} / \mathrm{L} \text { por dia, } \\
\text { 4-6 mEq/L por dia (em pacientes com alto risco } \\
\text { de desmielinização) }\end{array}$ \\
\hline & $\begin{array}{l}\text { Limites: } 10-12 \mathrm{mEq} / \mathrm{L} \text { por dia, } \\
8 \mathrm{mEq} / \mathrm{L} \text { por dia (em pacientes com alto risco de } \\
\text { desmielinização) }\end{array}$ \\
\hline \multirow[t]{2}{*}{ Manejo das correções excessivas } & $\begin{array}{l}\text { Natremia prévia à correção } \geq 120 \mathrm{mEq} / \mathrm{L}: \\
\text { Provavelmente desnecessária }\end{array}$ \\
\hline & $\begin{array}{l}\text { Natremia prévia à correção }<120 \mathrm{mEq} / \mathrm{L}: \\
\text { Iniciar água livre de eletrólitos ou desmopressina } \\
\text { quando a correção exceder } 6-8 \mathrm{mEq} / \mathrm{L} \text { por dia }\end{array}$ \\
\hline
\end{tabular}

Fonte: Hoorn e Zietse, 2017 (3).

A Tabela 1 mostra as soluções e suas respectivas concentrações de $\mathrm{Na}^{+}(1,4)$ :

Tabela 1 - Fórmula da hiponatremia.

\begin{tabular}{|l|l|}
\hline Solução: & Concentração de $\mathrm{Na}^{+}$em $\mathrm{mEq} / \mathrm{Litro}$ \\
\hline NaCl a 20\% & 3400 \\
\hline NaCl a 5\% & 855 \\
\hline NaCl a 3\% & 514 \\
\hline SF a 0,9\% & 154 \\
\hline Plasma & 140 \\
\hline Ringer lactato & 130 \\
\hline NaCl a $0,45 \%$ & 77 \\
\hline SG a 5\% & 0 \\
\hline
\end{tabular}

\subsection{Exercício}

Paciente feminina de 44 anos, com massa corpórea de $60 \mathrm{~kg}$ e diagnóstico prévio de neoplasia de pulmão, do tipo pequenas células, evoluiu com convulsões e estado torporoso. $[\mathrm{Na}+]$ plasmático $=110 \mathrm{mEq} / \mathrm{L}$. Qual o diagnóstico e conduta?

Resposta: A paciente apresenta uma hiponatremia classificada como profunda ([Na+] plasmático inferior a $125 \mathrm{mEq} / \mathrm{L}$ ), sintomática grave (presença convulsões e torpor). Frente a um paciente com sintomas grave, deve-se realizar bôlus de $100 \mathrm{~mL}$ de $\mathrm{NaCl}$ a $3 \%$, em 10 minutos, em até no máximo 3 vezes, para que os sintomas cessem. Uma vez que os sintomas graves se ausentem, a paciente deve receber em bomba de infusão $\mathrm{NaCl}$ $3 \%$, de $0.5-2 \mathrm{ml} / \mathrm{kg}$ por hora, objetivando uma correção de $6-8 \mathrm{mEq} / \mathrm{L}$ por dia. Ou seja, atingindo um $[\mathrm{Na}+]$ plasmático próximo de $118 \mathrm{mEq} / \mathrm{L}$. Se ultrapassar este valor, deve iniciar medidas para reduzir a natremia da paciente, como a infusão de soro glicosado a 
5\% (SG 5\%) ou desmopressina para reduzir a natremia e a consequente possibilidade de lesão cerebral devida à correção excessiva da tonicidade plasmática.

Assim que a paciente foi estabilizada do quadro neurológico, deve-se investigar a etiologia dessa hiponatremia. Lembre-se a hiponatremia não é uma doença, e sim uma manifestação subjacente de uma doença de base. No caso em questão, a paciente possui um diagnóstico prévio de carcinoma de pulmão do tipo pequenas células. Esse tipo de neoplasia, por ser neuroendócrina, é uma das principais causas de SIAD, sendo esta uma hipótese que deve ser investigada, a começar pelo exame físico, focando no status volêmico, principalmente. Outra possibilidade é uso de medicamentos, como os próprios quimioterápicos que podem também causar SIAD ou apenas hiponatremia por outro mecanismo fisiopatológico. A fim de uma avaliação etiológica mais racional, deve-se investigar a volemia do paciente, osmolaridade plasmática e urinária e, se necessário, o sódio urinário, ácido úrico e outros eletrólitos e solutos plasmáticos e urinários. Dessa forma, podendo tratar a sua causa da maneira mais adequada (Quadro 5).

Quadro 5 - Pontos importantes da hiponatremia.

- Em pacientes com hiponatremia hipervolêmica (insuficiência cardíaca congestiva, cirrose, insuficiência renal crônica avançada...) não se usa $\mathrm{NaCl}$ a $3 \%$ isoladamente, pois isso aumenta a volemia do paciente, agravando seu quadro clínico. Assim, se necessário o seu uso - como em casos sintomáticos deve-se associar o uso de diuréticos de alça;

- A solução escolhida para reposição deve possuir osmolaridade superior à osmolaridade urinária do paciente, caso contrário vai diluir ainda mais o CEC e agravar a hiponatremia;

- Muitas vezes os hospitais não possuem $\mathrm{NaCl}$ a 3\%, então temos que preparar a solução:

-Abra um 1 litro de água destilada e despreza $150 \mathrm{ml}$. Em seguida, acrescenta-se 15 ampolas de $\mathrm{NaCl}$ a $20 \%(150 \mathrm{ml})$. Sabendo que 1 ampola de $10 \mathrm{ml}$ de $\mathrm{NaCl}$ tem $34 \mathrm{mEq}$, então 15 ampolas diluídas num volume total de 1 litro $(850 \mathrm{ml}$ de água destilada mais $150 \mathrm{ml} \mathrm{de} \mathrm{NaCl}$ a $20 \%$ ) tem o total de $510 \mathrm{mEq}$ em 1 litro (15 ampolas x $34 \mathrm{mEq}$ ) de sódio).

\section{Hipernatremia}

\subsection{Definição}

Como já foi dito, os distúrbios do $\mathrm{Na}^{+}$estão intimamente associados com o controle da água corporal, de modo que qualquer deturpação dos mecanismos envolvidos na homeostase da água (sede, $\mathrm{ADH}$ e rins) ocasiona mudanças na concentração de $\mathrm{Na}$ + no organismo. Quando a concentração natrêmica é superior a $145 \mathrm{mEq} / \mathrm{L}$, diagnostica-se a hipernatremia. Esta, ao contrário da hiponatremia, sempre vai ser hiperosmolar hipertônica, justificando os seus sinais e sintomas por meio da desidratação celular a nível cerebral $(1,2,4,5)$.

\subsection{Etiologia}

Os principais mecanismos que protegem o corpo da hipernatremia são o da sede e da 
ação do ADH. A tonicidade plasmática aumentada é percebida no hipotálamo, gerando a sensação de sede que é sanada por meio da ingesta de água quase que instantaneamente. Também há a estimulação da liberação do $\mathrm{ADH}$, atuante na reabsorção de água livre a nível renal. Ou seja, qualquer alteração que não permita a ingesta de água ou expressão de sede (idosos com sensório reduzido, coma, ventilação mecânica, tumores hipotalâmicos, sarcoidose), bem como a inibição da atividade plena do ADH podem culminar na diminuição da água corporal total, o que aumenta a concentração de sódio. Ainda, a hipernatremia pode se originar por meio do aumento do ganho de $\mathrm{Na}+$, como ocorre em algumas iatrogenias $(1,2,4,5)$.

Essas causas podem alterar a volemia do paciente, uma vez que o $\mathrm{Na}^{+}$é o principal responsável por expandir ou contrair o CEC $(1,2,5)$. Assim, o status volêmico auxilia na investigação da etiologia da hipernatremia.

A administração de soluções hipertônicas de $\mathrm{NaCl}$ ou de bicarbonato de sódio causa hipernatremias hipervolêmica, pois o $\mathrm{Na}^{+}$em demasia expande o CEC.

Quando há perda de $\mathrm{Na}+$ e água, sendo esta última proporcionalmente maior, corroborase para quadro de hipernatremia hipovolêmica. Perdas renais, como ocorrem nas diureses osmóticas (situações em que a urina está com a tonicidade aumentada, como por exemplo quando há muita glicose, manitol e ureia) é uma situação em que o paciente se encontra em hipovolemia. Outra forma é a perda extrarrenal, que pode ocorrer por perda cutânea, hiperventilação e perda gastrintestinal. Para distinguir se a perda é renal ou extrarrenal, o $\mathrm{Na}+$ urinário é útil. Na primeira, o $\left[\mathrm{Na}^{+}\right]$urinário é superior a $20 \mathrm{mEq} / \mathrm{L}$, enquanto na segunda é menor que $20 \mathrm{mEq} / \mathrm{L}$ (1).

As hipernatremias euvolêmicas decorrem da perda ou da falta de ingesta de água. As perdas podem ser renais e extrarrenais. A carência de água está presente quando há lesão no SNC, inibindo o mecanismo da sede ou quando o indivíduo não consegue manifestar a sua sede ou está privado de acesso à água. Em relação aos pacientes hipernatrêmicos e normovolêmicos com perda de origem renal, a principal causa é a diabetes insipidus (DI) (Quadro 6), caracterizando -se pelos seguintes critérios $(1,5)$ :

Quadro 6 - Critérios hipernatrêmicos diabéticos.
1) Débito urinário $>4 \mathrm{ml} / \mathrm{kg} / \mathrm{h}$;
2) $\left[\mathrm{Na}^{+}\right]_{\text {sérico }}>145 \mathrm{mEq} / \mathrm{L}$;
3) Densidade urinária diminuída
4) Osmolaridade plasmática $\geq 300 \mathrm{mOsm}$;
5) Osmolaridade urinária $\leq 200 \mathrm{mOsm}$.

Após feito o diagnóstico de DI, deve-se investigar se a retenção hídrica está ocorrendo por falta da liberação do $\mathrm{ADH}$ (disfunção neuroendrocrinogênica) ou por resistência renal ao hormônio (disfunção nefrogênica). Para isso, é necessária uma avaliação do eixo ADH-rim, que é realizada por meio da análise da osmolaridade urinária após a aplicação de ADH exógeno. Ou seja, após a aplicação de $10 \mathrm{mcg}$ de desmopressina (DDAVP) por via nasal, ou 5 unidades de vasopressina aquosa por via subcutânea, espera-se um aumento da osmolaridade urinária em $50 \%$ ou mais, denunciando uma DI central $(1,5)$. Em contrapartida, se não houver alteração significativa na osmolaridade urinária, há uma resistência renal ao hormônio, denunciando uma DI nefrogênica. Entretanto, quando as funções renais e hipotalâmicas estiverem intactas, a administração de DDAVP pouco efeito fará na osmolaridade urinária, que estará acima de $700 \mathrm{mOsm} / \mathrm{kg}$ (1). Isto é, para realizar esse teste do ADH-rim, primeiro deve-se fazer o diagnóstico de DI $(1,5)$.

O Quadro 7 a seguir esquematiza as etiologias: 
Quadro 7 - Causas de hipernatremia.

1) Perda de água livre (euvolemia ou hipovolemia)

Perdas insensíveis

Hipodipsia

Causado por ingestão de etanol (transitório)

Diabetes insipidus

*Critérios de diagnóstico:

1. Débito urinário $>4 \mathrm{ml} / \mathrm{kg} / \mathrm{h}$;

2. $\left[\mathrm{Na}^{+}\right]_{\text {sérico }}>145 \mathrm{mEq} / \mathrm{L}$;

3. Densidade urinária diminuída;

4. Osmolaridade plasmática $\geq 300 \mathrm{mOsm}$;

5. Osmolaridade urinária $\leq 200 \mathrm{mOsm}$

Nefrogênico (ADH independente) congênito/adquirido:

- Doença renal

- Hipercalcemia ou hipopotassemia

- Drogas (lítio, foscarnet, metoxiflurano, anfotericina $\mathrm{B}$, antagonistas do receptor V2 da vasopressina)

Neurogênico (ADH dependente):

-Pós-traumático

- Tumores, cistos, histiocitose, tuberculose, sarcoidose

- Idiopático

- Aneurismas, meningite, encefalite ou Síndrome de Guillain - Barret

\section{2) Perda de fluído hipotônico (hipovolemia)}

\begin{tabular}{|c|c|c|}
\hline $\begin{array}{c}\text { Causas renais } \\
\left(\left[\mathrm{Na}^{+}\right]_{\text {urinário }}>20 \mathrm{mEq} / \mathrm{L}\right):\end{array}$ & $\begin{array}{l}\text { Causas gastrintestinais } \\
\left(\left[\mathrm{Na}^{+}\right]_{\text {urinário }}<20 \mathrm{mEq} / \mathrm{L}\right) \text { : }\end{array}$ & $\begin{array}{c}\text { Causas cutâneas } \\
\left(\left[\mathrm{Na}^{+}\right]_{\text {urinário }}<20 \mathrm{mEq} / \mathrm{L}\right):\end{array}$ \\
\hline $\begin{array}{l}\text { - Diuréticos de alça } \\
\text { - Diurese osmótica } \\
\text { (glicose, ureia, manitol) } \\
\text { - Diurese pós-obstrutiva } \\
\text { - Fase poliúrica da necrose } \\
\text { tubular aguda } \\
\text { - Doença renal intrínseca }\end{array}$ & $\begin{array}{l}\text {-Vômitos e diarreias } \\
\text { - Drenagem nasogástrica } \\
\text { - Fístula enterocutânea } \\
\text { - Uso de agentes catárticos } \\
\text { osmóticos (lactulose) }\end{array}$ & $\begin{array}{l}\text { - Queimaduras } \\
\text { - Sudorese excessiva }\end{array}$ \\
\hline $\begin{array}{l}\text { Infusão de bicarbonato de } \\
\text { Dieta enteral hipertônica } \\
\text { Ingestão de cloreto de sód }\end{array}$ & sódio hipertônico & \\
\hline \multicolumn{3}{|c|}{ Infusão de cloreto de sódio hipertônico } \\
\hline \multicolumn{3}{|c|}{ Diálise hipertônica } \\
\hline \multicolumn{3}{|c|}{$\begin{array}{l}\text { Hiperaldosteronismo primário } \\
\text { Síndrome de Cushing (reabsorção intensa de sódio }\end{array}$} \\
\hline
\end{tabular}

Fonte: LOPES, A. C. Clínica médica: diagnóstico e tratamento (1).

\subsection{Quadro clínico}

O quadro clínico depende da intensidade do grau de desidratação dos neurônios, podendo o paciente se apresentar assintomático ou até em coma. Os sinais e sintomas mais comuns são letargia, irritabilidade, inquietude, hiperreflexia, espasticidade, febre, náuseas, vômitos, dispneia e sede intensa. Este último pode estar presente no início, mas 
depois se ausenta conforme a hipernatremia se acentua. Os quadros mais graves ocorrem quando há uma elevação súbita da concentração de Na+ sérico superior a $158 \mathrm{mEq} / \mathrm{L}$. Nessas situações, com a brusca hipertonicidade plasmática, transloca-se mais intensamente a água intracelular, de modo que o volume cerebral reduz, podendo romper veias intracranianas. Assim, paciente hipernatrêmicos podem se apresentar com hemorragia intracranianas focais e na subaracnoide que justificam lesões neurológicas irreversíveis $(1,2,4,5)$.

É importante frisar que, assim como na hiponatremia, as células nervosas possuem um mecanismo de adaptação ao aumento da tonicidade plasmática. Inicialmente, a desidratação celular é compensada com o ingresso da água oriunda do líquido cefalorraquidiano para o cérebro, a fim de aumentar o seu volume intersticial. Em seguida, há mobilização de sódio e potássio e, depois, os de osmólitos, como o mioinositol, taurina e glutamato que aumentam a tonicidade do meio intracelular para o ingresso de água. Todo esse processo demora menos de um dia para ocorrer, sendo preservado por dias. Com isso, pode-se ter pacientes com concentrações elevadas de sódio, porém assintomáticos $(2,5)$.

\subsection{Tratamento}

Primordialmente, inicia-se com a identificação e correção dos fatores que geraram ou contribuem para o desequilíbrio natrêmico, quando possíveis $(1,4,5)$ (Quadro 10). Por exemplo: inibição da perda gastrintestinal, hiperglicemia, controle da febre, hipercalcemia e outras. Na ocorrência de convulsões, deve-se proteger a via aérea e fazer o controle do quadro com anticonvulsivantes.

Para estimar o quão agressivo vai ser a correção hidroeletrolítica, deve-se avaliar se há ou não a compensação celular frente a desidratação celular por meio do tempo de início do quadro. Assim, pode-se estimar se a célula está ou não hipertônica, pois se estiver em relação ao plasma recém retificado, culminará na translocação água para o meio celular, gerando então o edema cerebral $(1,2,4,5)$. Portanto (Quadro 8):

Quadro 8 - Taxas de correção na hipernatremia.

- Se hipernatremia aguda (com início de poucas horas) $\rightarrow$ Velocidade de correção de $1 \mathrm{mEq} / \mathrm{L} / \mathrm{h}$;

- Se hipernatremia crônica de (> 48 horas ou de duração desconhecida) Velocidade de $0,5 \mathrm{mEq} / \mathrm{L} / \mathrm{h}$.

- Se $\left[\mathrm{Na}^{+}\right]_{\text {plasmático }}>160 \mathrm{mEq} / \mathrm{L} \rightarrow$ A correção deve ser feita entre 48 - 72horas.

Para a reposição de fluídos, a via preferencial é oral (1). Porém, caso indisponível, a via intravenosa está indicada para a infusão de soluções hipotônicas, como o soro fisiológico a $0,45 \%$ e o soro glicosado que são os mais usados. Porém, quando o paciente está com instabilidade hemodinâmica se faz obrigatório o uso de solução intravenosa, idealmente soro fisiológico a $0,9 \%$ ou Ringer lactato até que se reverta o quadro $(1,4,5)$. Após isso, volta-se à infusão de solução hipotônica. Em ambos os casos, sempre se respeita a correção máxima de 8 - $10 \mathrm{mEq} / \mathrm{L}$ por dia $(1,2,5)$.

Depois de escolher o fluido, calcula-se o volume a ser reposto somado às perdas insensíveis. A tabela a seguir mostra os fluidos mais usados, as suas respectivas concentrações de $\mathrm{Na}+\mathrm{e}$ as fórmulas usadas para o cálculo (Quadro 9). 
Quadro 9 - Fórmulas da hipernatremia.

\begin{tabular}{|c|c|c|}
\hline \multicolumn{3}{|c|}{$\begin{array}{c}\text { Mudança do } \mathrm{Na}^{+} \text {sérico }(\mathrm{mEq} / \mathrm{L})=\frac{\mathrm{Na}^{+} \text {infusão }-\mathrm{Na}^{+} \text {sérico }}{\text { Água corporal }+1} \\
\text { cit de água livre }=\left(\left[\mathrm{Na}^{+}\right]_{\text {Plasmático desejado }-140) \times \text { áqua corporal total }}\right. \\
140\end{array}$} \\
\hline Solução: & Situação indicada: & $\begin{array}{l}\text { Concentração de } \\
\mathrm{Na}^{+}:\end{array}$ \\
\hline Soro glicosado (SG) & Perda de água livre & 0 \\
\hline Soro fisiológico (SF) a 0,9\% & \multirow[b]{2}{*}{$\begin{array}{l}\text { Hipovolemia } \\
\text { instabilidade } \\
\text { hemodinâmica, } \\
\text { reversão do } \\
\text { circulatório }\end{array}$} & 154 \\
\hline Ringer lactato & & 130 \\
\hline Solução de $\mathrm{NaCl}$ a $0,45 \%$ & Paciente euvolêmico & 77 \\
\hline $\begin{array}{l}\text { Solução de NaCl a } 0,2 \%+ \\
\text { SG a } 5 \%\end{array}$ & $\begin{array}{l}\text { Hipernatremia } \\
\text { hipovolemia }\end{array}$ & 34 \\
\hline \multicolumn{3}{|c|}{$\begin{array}{l}\text { Água corporal total }=\text { Peso } x 0,6 \rightarrow \text { se homem ou criança } \\
\text { Peso } x 0,5 \rightarrow \text { se homem idoso ou mulher } \\
\text { Peso } x 0,45 \rightarrow \text { se mulher idosa } \\
\text { * Observação: a constante muda em relação à situação de hipernatremia, pois se } \\
\text { estima-que em situação de hipernatremia os idosos possuem menos água corporal } \\
\text { total. }\end{array}$} \\
\hline & & \\
\hline
\end{tabular}

Fonte: LOPES, A. C. Clínica médica: diagnóstico e tratamento (1).

O tratamento da DI depende do seu subtipo (1):

Quadro 10 - Tratamento do subtipo de diabetes insipidus (DI).

Diabetes insipidus central $\rightarrow$ Infusão contínua, intravenosa, de vasopressina em doses menores que $2,4 \mathrm{U} / \mathrm{h}$ ou com DDAVP intermitente na dose de $1-4$ microgramas, endovenoso, em bolus, seguido de $1-2$ microgramas, endovenoso, a cada 6 horas até atingir a diurese $<4 \mathrm{ml} / \mathrm{kg} / \mathrm{h}$.

Diabetes insipidus nefrogênico $\rightarrow$ Pode-se empregar o uso de AINES, diuréticos tiazídicos (amilorida 2,5 - 10mg/dia, no caso dos usuários de lítio) a fim de reduzir a poliúria, principalmente em pacientes crônicos. Para os agudos com DI secundário ao lítio, geralmente o aumento da ingesta de água é capaz de compensar a poliúria.

\subsection{Exercício}

Paciente masculino de 21 anos, massa corpórea de $70 \mathrm{~kg}$, é trazido por familiares ao pronto-atendimento em estado torporoso após ter tido episódios de convulsão há aproximadamente 30 minutos. Os acompanhantes relatam que o paciente tem diagnóstico prévio de transtornos psiquiátricos e faz uso de carbonato de lítio há 2 meses para o controle dos sintomas maníacos. Nos últimos 2 dias ele estava indo muitas vezes ao banheiro para urinar, então o paciente resolveu dobrar a dose do medicamento por achar que sanaria seu problema. Ao exame físico, mostra-se com a boca seca e mucosas 
ressecadas, eupneico, frequência cardíaca de 102 bpm e com PA de 100/ $70 \mathrm{mmHg}$. O $[\mathrm{Na}+]$ Plasmático $=160 \mathrm{mEq} / \mathrm{L}$. Qual o diagnóstico e conduta?

Resposta: O paciente se apresenta em hipernatremia severa $([\mathrm{Na}+] \mathrm{Plasmático}=160$ $\mathrm{mEq} / \mathrm{L}$ ) muito provavelmente secundária à superdosagem do lítio sem o devido controle. A história de poliúria é muito sugestiva que ocorreu uma resistência ao ADH a nível renal, secundária à nefrotoxicidade do lítio, principalmente nos túbulos coletores, impedindo a adequada reabsorção de água livre, que culminou no diabetes insipidus nefrogênico. Esta, por sua vez, agravou-se a tal ponto de gerar uma hipernatremia hipovolêmica severa aguda.

Por se tratar de um quadro agudo, os mecanismos celulares compensatórios não são tão intensos, o que torna permissivo uma correção mais agressiva, condizente com 1 $\mathrm{mEq} / \mathrm{L} / \mathrm{h}$. Entretanto, ainda há o risco de se gerar um edema cerebral iatrogênico se a variação do sódio sérico for superior a $10 \mathrm{mEq} / \mathrm{L} /$ dia. Portanto, [Na+]Plasmático desejado é de 150 (160-10).

Como o paciente se encontra hipovolêmico (desidratado) com estabilidade hemodinâmica, a prioridade deve ser restabelecer a volemia do paciente com soluções isotônicas (Ringer Lactato ou soro fisiológico 0,9\%), não alterando de modo significativo a sua concentração plasmática. Posteriormente, inicia-se a correção do déficit de água. As opções ideais de soluções hipotônicas para essa tarefa são: SG5\%, solução salina $0,45 \%$ e solução salina 0,2\% com SG5\%. Em função de um quadro neurológico grave, secundário principalmente à perda de água livre, a solução ideal é o SG5\%, apesar de a correção também poder ser feita com as outras soluções. Agora que já se sabe a solução indicada, resta apenas calcular o volume de reposição de água livre após a restauração volêmica (Figura 1):

\section{Déficit de água livre $=\left(\left[\mathrm{Na}^{+}\right]\right.$Plasmático desejado - 140) $\mathrm{x}$ água corporal total

\section{Déficit de água livre $=(150-140) \times \underline{0,6 \times 70}$

\section{Déficit de água livre $=10 \times \underline{42}=3$ litros}

Figura 1 - Cálculo do volume de reposição.

Ou seja, o paciente apresenta um déficit de água livre de 3 litros que resultam numa diminuição de $10 \mathrm{mEq} / \mathrm{L}$ no seu $\mathrm{Na}+$ sérico. Dessa forma, deve-se repor 3 litros nessas primeiras 24 horas, numa velocidade de $1 \mathrm{mEq} / \mathrm{L} / \mathrm{h}$ (que durará então num total de 10 horas) para correção máxima permitida. Para calcular quantas $\mathrm{ml} / \mathrm{h}$ correspondem a variação de $1 \mathrm{mEq} / \mathrm{L} / \mathrm{h}$, pode-se fazer uma regra de três simples (Figura 2):

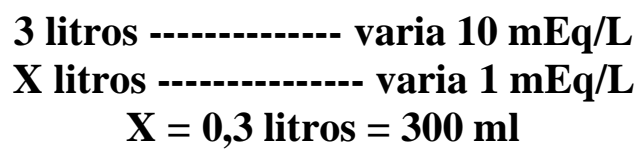

Figura 2 - Cálculo proporção $\mathrm{ml} / \mathrm{h}$ com variação de $1 \mathrm{mEq} / \mathrm{L} / \mathrm{h}$.

Então, para alterar $1 \mathrm{mEq} / \mathrm{L} / \mathrm{h}$ tem que se infundir $300 \mathrm{ml} / \mathrm{h}$ no paciente. Nesse ritmo, em 10 horas, os 3 litros máximos previstos serão infundidos. No dia seguinte, calcula-se novamente o déficit de água livre e a velocidade de infusão para, finalmente, normalizar 
a natremia do paciente.

Por fim, resta apenas a correção das perdas insensíveis:

Perdas insensíveis por dia $=$ Peso $\times 10 \mathrm{ml}$

Perdas insensíveis por dia $=70 \times 10 \mathrm{ml}=700 \mathrm{ml}$ por dia

Então a prescrição de 24 horas fica:

$3.700(3000+700) \mathrm{ml}$ de SG5\% na velocidade de infusão de $300 \mathrm{ml} / \mathrm{h}$

No dia seguinte, com uma nova mensuração do sódio sérico, deve-se calcular novamente a reposição hídrica, levando em consideração o seu status clínico e as perdas insensíveis.

Para encerrar sobre os distúrbios do sódio, alguns pontos importantes são frisados (Quadro 11):

Quadro 11 - Pontos importantes da hipernatremia.

- A volemia e o estado clínico do paciente em correção do seu distúrbio deve ser feita a cada $2-4$ horas para evitar complicações, principalmente o edema cerebral;

-Alguns serviços de saúde não possuem soluções hipotônicas, fazendo-se necessário que se produza a solução com as seguintes misturas: $(3: 1)$;

- $750 \mathrm{ml}$ de água destilada $+\mathbf{2 5 0} \mathrm{ml}$ de SF $0,9 \%=$ solução salina a $0,2 \%$ $(1: 1)$.

- $500 \mathrm{ml}$ de água destilada $+\mathbf{5 0 0} \mathrm{ml}$ de SF $0,9 \%$ = solução salina a $0,45 \%$

- Pacientes que receberam infusão com SG 5\% devem ter a sua glicemia monitorizada. Se ocorrer episódios de hiperglicemia, o controle deve ser feito com insulinoterapia.

\section{Referências}

1. Vendrame LS, Lopes RD. Distúrbios do sódio. In: Lopes AC. Clínica médica: diagnóstico e tratamento. São Paulo: Editora Atheneu; 2013. p. 1877 - 88.

2. Sterns RH. Disorders of Plasma Sodium - Causes, Consequences, and Correction. N Engl J Med 2015; 372(1):55-65.

3. Hoorn EJ, Zietse R. Diagnosis and Treatment of Hyponatremia: Compilation of the Guidelines. J Am Soc Nephrol 2017; 28(5):1340-49.

4. Harring TR, Deal NS, Kuo DC. Disorders of Sodium and Water Balance. Emerg Med Clin N Am 2014; 32(2): 379-401.

5. Liamis G, Filippatos TD, Elisaf MS. Evaluation and treatment of hypernatremia: a practical guide for physicians. Postgraduate Medicine 2016; 128(3):299-306.

6. Sterns RH, Silver SM. Complications and management of hyponatremia. Curr Opin Nephrol Hypertens 2016; 25(2):114-9.

7. Cuesta M, Thompson CJ. The syndrome of inappropriate antidiuresis (SIAD). Best Practice \& Research Clinical Endocrinology \& Metabolism 2016; 30(2); 175-87. 